\title{
INFORMAÇÃO E CONCEITUAÇÃO A dimensão cognitiva da desigualdade política entre jovens de Belo Horizonte*
}

\author{
Mario Fuks \\ Frederico Batista Pereira
}

\section{Introdução}

Para compreender como os cidadãos tomam suas decisões políticas, diversos estudiosos identifi-

* O presente artigo apresenta resultados parciais da pesquisa "O Parlamento Jovem como espaço de socialização política”, financiada pelo CNPq e pela Fundação de Amparo à Pesquisa de Minas Gerais (Fapemig). A pesquisa contou com a assessoria técnica e supervisão de campo de Maria Aparecida Machado Pereira. Participaram Fabrícia de Almeida Costa, Ana Luísa da Cunha Pinheiro, Angel Dornelas Trindade, Amanda Horta Campos, Leôncio Farias, Karla Juliana Onofre e Liliane da Conceição Rosa, alunos do curso de Ciências Sociais da Universidade Federal de Minas Gerais. De fundamental importância para assegurar qualidade na produção dos dados da pesquisa foi o apoio da Cinthia Barros e do Fabrício Fialho. Agradecemos a Jorge Alexandre Barbosa Neves e Cristine Campos de Xavier Pinto pelas sugestões metodológicas.

Artigo recebido em janeiro/2010

Aprovado em fevereiro/2011 cam a sofisticação política como elemento-chave na explicação do comportamento político. A premissa teórica comum é a de que eleitores com níveis distintos de sofisticação teriam apreensões distintas do universo da política, de modo que isso influenciaria a maneira como tomariam suas decisões políticas (Campbell et al., 1960; Sniderman, Brody e Tetlock, 1991; Delli Carpini e Keeter, 1996). Tal condição de desigualdade na distribuição da sofisticação política tem sido atribuída à posição socioeconômica dos cidadãos, além do interesse por política (Neuman, 1986; Luskin, 1990; Delli Carpini e Keeter, 1996). ${ }^{1}$

O estudo da sofisticação política suscita duas inquietações que pretendemos explorar. A primeira delas remete aos problemas relacionados com a elaboração analítica do conceito. As propostas para o estudo do conhecimento político lidam com duas dimensões principais, uma referida ao volume e à amplitude de informações políticas dos cidadãos e 
outra, à articulação das cognições por meio de um entendimento mais abstrato ou conceitual da política. Uma primeira indagação de natureza conceitual é se cada uma dessas duas dimensões integra, de fato, o constructo "sofisticação política".

$\mathrm{Na}$ elaboração analítica do conceito de sofisticação política, a mensuração desse tipo de conhecimento ocupa lugar de destaque. Ao contrário de renda, ocupação profissional, raça e sexo, a sofisticação política refere-se a um atributo que não pode ser medido diretamente. Sua mensuração depende da elaboração de um indicador capaz de captar o grau de compreensão dos conceitos mais abstratos da política, tais como esquerda-direita e liberal-conservador. As declarações dos indivíduos a respeito das informações que têm sobre assuntos, atores e instituições políticas constituem o meio exclusivo de acesso a esse universo.

O segundo tipo de inquietação refere-se às causas da desigualdade na distribuição da sofisticação política entre a população. Uma das grandes agendas de pesquisa que aborda a origem e a formação desta desigualdade é aquela proposta por estudos sobre socialização política dos jovens. Esses estudos buscam compreender como se produzem, nessa fase da vida, as desigualdades políticas verificadas entre os cidadãos já adultos no que se refere ao conhecimento (Niemi e Junn, 1998) e outros aspectos da vida política (Verba, Burns e Scholozman, 2003). Quais seriam as experiências de socialização dos jovens que os proveriam de maior ou menor conhecimento sobre política (Sears e Valentino, 1997)? Que tipos de ambiente tenderiam a proporcionar experiências capazes de estimular a aquisição de tal conhecimento? Experiências socializadoras distintas propiciariam igual aumento em cada um dos tipos específicos de conhecimento sobre política, nos termos apresentados acima?

O presente artigo dedica-se a examinar teórica e empiricamente essas questôes. A próxima seção consiste em uma discussão a respeito de alguns dos trabalhos que contribuem tanto para a elaboração teórica como para o aprimoramento da mensuração do conhecimento sobre política. A partir de um diálogo crítico com a literatura, serão construídas medidas dos dois tipos de conhecimento político: a posse de informaçôes factuais e o domínio concei- tual da política. Esta seção consistirá basicamente na realização de testes de confiabilidade das medidas de conhecimento político discutidas.

$\mathrm{Na}$ última seção, avaliaremos, por meio dos procedimentos de validação das duas medidas, até que ponto a distinção entre os dois tipos de conhecimento político é relevante no que se refere aos contextos e às experiências que os causariam. Essa parte final do artigo busca também contribuir para a discussão dos determinantes da distribuição desigual de conhecimento político e, consequentemente, da desigualdade política.

Os dados utilizados provêm da pesquisa de painel "O Parlamento Jovem como espaço de socialização política”, que entrevistou 351 jovens secundaristas de Belo Horizonte em duas ondas ao longo do ano de $2008 .^{2}$

\section{Conceito e mensuração}

A ideia de que o público seria estratificado conforme o grau de conhecimento dos cidadãos a respeito dos assuntos políticos remonta pelo menos ao estudo clássico da chamada Escola de Michigan (Campbell et al., 1960). Desde então, diversas terminologias têm sido empregadas para designar o domínio cognitivo por meio das informações e conceitos vinculados a assuntos políticos. Sofisticação (Converse, 1964; Neuman, 1986; Luskin, 1987, 1990; Sniderman, Brody e Tetlock, 1991), conhecimento (Delli Carpini e Keeter, 1996; Niemi e Junn, 1998), expertise (Krosnick, 1990), entre outros, são alguns dos termos diferentes referidos a construtos teóricos muito semelhantes.

O estudo de Philip Converse (1964) a respeito da estruturação ideológica dos cidadãos foi certamente pioneiro em tratar o entendimento que os cidadãos teriam do mundo da política. Para ele, o entendimento da política, embora conceitualmente único, manifesta-se de duas formas. A primeira é a posse de um sistema de crenças, isto é, da configuração de ideias que se integrariam de forma mais ou menos estruturada ou funcionalmente interdependente (Converse, 1964, p. 207). A segunda é pelo reconhecimento e entendimento das ideologias políticas que organizam o sistema político norte-ame- 
ricano, ou seja, o espectro liberal-conservador. Ela seria uma medida da capacidade de conceituação política dos cidadãos (Luskin, 1987).

Enquanto a estruturação do sistema de crenças tem sido questionada como componente da sofisticação política (Zaller e Feldman, 1992; Kuklinski e Quirk, 2002), ${ }^{3}$ o debate mais recente a respeito da capacidade de o indivíduo entender o que acontece no mundo da política tem sido mais receptivo aos ensinamentos de Converse. Nesse debate, um ponto de concordância parece ser o de que o conceito da sofisticação se desdobra em duas dimensões. Neuman referiu-se à habilidade de identificar e discriminar entre os diversos assuntos, pessoas e fatos da política como sendo a dimensão da diferenciação conceitual (Neuman, 1981, p. 1237). Já a organização das ideias e assuntos políticos em construtos mais abstratos seria a segunda dimensão da sofisticação política, a da integração conceitual (Idem, p. 1237). Luskin lançou mão de termos diferentes para se referir às mesmas dimensões. Inicialmente, o autor distinguiu três dimensōes principais (Luskin, 1987, p. 859): o tamanho ou o número de informações do cidadão; a amplitude de assuntos que tais informações cobrem no universo da política; e a organização ou a interconexão entre as informações ou cognições políticas do cidadão. Mais à frente, contudo, Luskin acabou admitindo que as duas primeiras dimensōes (tamanho e amplitude) poderiam ser entendidas como aspectos da noção de diferenciação conceitual de Neuman, e também concedeu que haveria convergência entre o que chamou de organização e noção de integração conceitual (Idem, p. 861).

A concordância termina quando se trata da mensuração das duas dimensões da sofisticação política, bem como do construto individual mais geral. O artigo de Luskin sobre o problema da mensuração da sofisticação política cobriu uma boa parte das controvérsias sobre o assunto. Como mostrou o autor, as medidas canônicas da dimensão da diferenciação conceitual seriam perguntas mais diretas sobre informaçōes factuais sobre política, e acrescentou que tais medidas seriam tão consistentes que poderiam até ser utilizadas como base para o construto mais geral da sofisticação (Idem, p. 890).
Outros estudos de grande relevância sobre o tema utilizaram exclusivamente esse tipo de medida. Delli Carpini e Keeter (1996, p. 10), por exemplo, optaram por falar em conhecimento político como um conceito mais restrito, referido ao conjunto de informações políticas factuais estocado na memória de longo prazo). Para os autores, esta noção permite construir indicadores mais objetivos de conhecimento, contando apenas com a precisão e a confiabilidade de medidas com respostas certas ou erradas. Niemi e Junn (1998, pp. 11-12), por sua vez, afirmaram que os argumentos e as evidências daqueles autores atestam a validade das medidas de posse de informações factuais como expressão adequada do conceito mais geral da sofisticação política.

No que se refere às medidas de integração conceitual, Neuman (1981) utilizou a análise de conteúdo de entrevistas em profundidade para elaborar sua medida. Além de enumerar as referências dos respondentes a conceitos abstratos, Neuman pediu que os codificadores das entrevistas fizessem uma avaliação quanto aos padrões mais gerais de organização, conexão e contraste entre as idéias encontradas nas entrevistas de cada respondente. De acordo com Neuman (1981, p. 1248), as avaliaçóes feitas por codificadores diferentes apresentaram alta correlação entre si, conferindo consistência à medida.

Não é difícil perceber por que a construção de instrumentos adequados para captar a capacidade de integração conceitual dos cidadãos é um dos principais pontos controversos em relação à mensuração da sofisticação política. Os críticos das medidas de integração conceitual alegam que estas seriam pouco confiáveis porque sua mensuração seria afetada pela mera recordação de termos políticos abstratos que o entrevistado ouviu recentemente. Os respondentes de surveys não dariam suas respostas com base no domínio do sentido semântico das noçôes empregadas, que seria justamente a habilidade a ser testada. Nesse sentido, conforme vimos, muitos estudiosos optaram por basear suas pesquisas apenas nas medidas de posse de informações factuais, alegando que tal dimensão seria representativa do construto mais geral da sofisticação política (Luskin, 1987; Delli Carpini e Keeter, 1996; Niemi e Junn, 1998). ${ }^{4}$ 
A medida de conhecimento conceitual elaborada no presente artigo lida com tais dificuldades de duas maneiras. Primeiramente, em vez de se basear em apenas uma pergunta aberta para codificar as respostas obtidas, o que tornaria complicada a confiabilidade do construto final, solicitamos aos entrevistados que dissessem cinco expressões associadas aos termos "esquerda" e "direita". A repetição ajuda a resolver o problema da confiabilidade identificado por Luskin (1987, p. 882), pois a mensuração repetida de um mesmo indicador tende a aumentar a confiabilidade do construto gerado a partir dos itens (Carmines e Zeller, 1980, p. 54). Os respondentes que, no formato de pergunta individual, "chutariam" respostas corretas acessíveis na memória de curto prazo seriam mais exigidos no formato da bateria de expressões. Nesse sentido, os indivíduos com maior capacidade de prosseguir fornecendo respostas tenderiam a ser aqueles que, de fato, possuem expressões associadas aos termos direita e esquerda na memória de longo prazo.

Em segundo lugar, e ainda mais central em nossa proposta, foi a codificação bidimensional das respostas obtidas. O exame das expressões utilizadas pelos entrevistados nos levou a perceber a existência de duas dimensões distintas da manifestação do conhecimento conceitual. A primeira refere-se ao grau de abstração da resposta. Quanto mais abstrata a expressão associada à esquerda ou à direita, maior a capacidade de conceituação do respondente. Expressōes como "comunismo" ou "política social" têm escore maior do que "Lula" ou "Fidel Castro".

Descobrimos, na codificação das expressões, que, embora seja condição necessária, a abstração não é condição suficiente para que um indivíduo se situe no topo do ranking da sofisticação política. Por exemplo, um respondente que dissesse "liberalismo" como expressão referida ao termo "esquerda" não poderia ter o mesmo escore final, no índice de conceituação, que aquele que dissesse "comunismo".

Sendo a codificação por abstração, por si só, incompleta, a solução foi desenvolver outro eixo de codificação, levando em conta o grau de proximidade semântica da expressão verbalizada em relação aos termos direita e esquerda. Tal eixo nos permitiu identificar que, embora não envolva abstração, os termos "Lula" e "Fidel Castro" estão mais próximos da família semântica do "comunismo" do que o "liberalismo" e, nesse eixo, esses termos têm um escore superior ao liberalismo.

A criação dos eixos de abstração e precisão semântica ajudou a dar conta da diversidade de respostas obtidas, o que supomos ser valioso para a construção de uma medida válida de conhecimento político de natureza conceitual. Os detalhes do procedimento de construção da variável serão descritos no próximo tópico.

Nosso próximo passo consiste em averiguar até que ponto as duas dimensões do conhecimento sobre política compartilham propriedades que permitam reduzir o conceito mais geral a uma ou outra delas sem a perda de informações analiticamente relevantes.

Antecipamos, aqui, a nossa hipótese: o entendimento conceitual é um tipo mais exigente de conhecimento político, implicando a posse de recursos cognitivos mais complexos do que a mera posse de informações factuais. Nosso estudo, portanto, reconhece e busca contribuir para a comprovação da validade explicativa da concepção de conhecimento político elaborada pelo The American Voter e, posteriormente, refinada por Converse. O que essa concepção traz de novo é tratar o conhecimento político como algo maior do que o conjunto de seus conteúdos, associado à capacidade de abstração e de organização dos conteúdos da política na mente do indivíduo.

Nesse sentido, a "virada" proposta por Converse no campo de estudos em pauta se assemelha ao que Kant fez na teoria do conhecimento e, depois dele, Durkheim importou para a sociologia do conhecimento. Em comum, esses três autores mostraram que as formas mediante as quais o conhecimento se estrutura constituem os fundamentos da atividade cognitiva. Desconsiderar essa inovação significa não superar as limitaçôes da visão convencional de conhecimento político.

O que se chamará, a partir daqui, de conhecimento conceitual ou sofisticação conceitual refere-se à integração conceitual das cognições políticas. A dimensão da diferenciação será chamada de "conhecimento factual” ou "informação política”. Reservamos o termo sofisticação política para a ideia 
mais ampla, indicando a localização do indivíduo dentro da "estratificação cognitiva" da sociedade.

\section{Construção dos índices}

Nossas análises são feitas a partir dos dados de uma pesquisa de survey feita, em 2008, com alunos do ensino médio de Belo Horizonte, capital do estado de Minas Gerais. Uma amostra não aleatória de $351 \operatorname{casos}^{5}$ foi elaborada com a finalidade de identificar os efeitos da participação no Parlamento Jovem mineiro ${ }^{6}$ sobre o conhecimento e as atitudes políticas de jovens.

As variáveis de conhecimento factual e conceitual foram construídas a partir de oito baterias de perguntas de conhecimento existentes no questionário. Cada um dos índices foi composto por quatro baterias. $\mathrm{O}$ índice de conhecimento factual foi construído a partir das seguintes variáveis:

1) Conhecimento do respondente a respeito de cargos e partidos de politicos proeminentes no pais - as questōes eram abertas e pediam aos respondentes que dissessem o cargo e o partido de quatro figuras políticas importantes no Brasil: Aécio Neves, Fernando Pimentel, José Serra e Martha Suplicy. Também foram perguntados o cargo e o país de Hugo Chaves. As questões foram pós-codificadas entre três níveis de acerto $(1=$ acerto completo; $0,5=$ acerto incompleto ou cargo/partido antigo; $0=$ erro ou não resposta). $\mathrm{O}$ índice final para esta variável foi feito pelo somatório dos escores obtidos em cada resposta.

2) Número de partidos que o respondente foi capaz de citar - esta bateria de questôes pedia que o respondente listasse os partidos que conhecia. A cada partido brasileiro falado corretamente ele ganhava um ponto, enquanto a não citação ou o erro valiam zero. $\mathrm{O}$ índice foi construído pelo somatório dos acertos. $\mathrm{O}$ índice varia de 0 a 11, o número máximo de partidos que os respondentes conseguiram mencionar.

3) Conhecimento do significado de siglas relevantes - foi pedido que os respondentes dissessem o significado das siglas TRE (Tribunal Regional Eleitoral), ONU (Organização das Naçōes Unidas), UNE (União Nacional dos Estudantes) e MST
(Movimento dos Sem-Terra). O índice foi feito somando as palavras corretamente mencionadas pelos respondentes, variando de 0 a 12 . Optou-se por essa codificação, em vez do acerto substantivo, devido à dificuldade de se classificar respostas parcialmente corretas.

4) Conhecimento da posição dos partidos no espectro ideológico - também foi pedido aos entrevistados que classificassem cinco partidos brasileiros (PT, DEM, PCdoB, PP e PSTU) como de esquerda ou de direita. ${ }^{7}$ Cada acerto valia um ponto e o erro ou não resposta valia zero. $O$ índice foi construído pelo somatório dos acertos, indo de 0 a 5 . Pode-se argumentar que tal índice revelaria também a capacidade dos respondentes de operarem com categorias mais abstratas de esquerda e direita. Entretanto, como a correta localização ideológica dos partidos não nos permite inferir o grau de sofisticação conceitual dos entrevistados, escolhemos essa variável como indicadora apenas da posse de informação política.

Para medir o grau de conceituação, utilizamos duas perguntas que revelam a habilidade do respondente para, nos termos de Luskin (1987, p. 881), "reconhecer e entender" conceitos mais abstratos da política. Uma delas pedia ao entrevistado cinco expressões que ele associasse ao termo "esquerda", enquanto a outra pedia o mesmo em relação ao termo "direita" ${ }^{8} \mathrm{O}$ procedimento gerou dois grupos com cinco respostas em cada. $\mathrm{O}$ passo seguinte foi, então, codificar as respostas em relação aos eixos de abstração e de precisão semântica, tal como discutido no tópico anterior. A partir das respostas obtidas, quatro escores foram construídos a fim de elaborar um índice mais geral da sofisticação conceitual dos respondentes.

1) Capacidade de vincular conteúdos e simbolos abstratos ao termo "esquerda", independentemente de acerto. Encontramos quatro níveis de resposta pós-codificados para cada uma das cinco expressōes mencionadas, sendo que as cinco respostas foram somadas para obter uma variável contínua:

3 = uso de conceitos abstratos, independentemente do teor semântico. Exemplos: comunismo, socialismo, autoritarismo, democracia, conservadorismo. 
2 = associação à dicotomia situação/oposição.

1 = associação a objeto concreto. Exemplos: partidos, pessoas, massa, povo, PT, Lula, trabalhadores.

0 = não resposta, incluindo apenas os indivíduos que não foram capazes de responder à pergunta.

2) Capacidade de vincular conteúdos e simbolos abstratos ao termo "direita", independentemente de acerto. Foram quatro os níveis de resposta pós-codificados, sendo que as cinco respostas foram somadas para obter uma variável contínua:

3 = uso de conceitos abstratos, independentemente do sentido semântico. Exemplos: capitalismo, economia, liberalismo, conservadorismo, democracia, socialismo.

2 = associação à dicotomia situação/oposição.

1 = associação a objeto concreto. Exemplos: elite, burguesia, classe dominante, partidos socialistas, PT.

0 = não resposta, incluindo apenas os indivíduos que não foram capazes de responder a pergunta.

3) Capacidade de expressar conteúdos e símbolos cujo conteúdo semântico se aproxima do termo "esquerda”, independentemente do nível de abstração. Foram quatro os níveis de resposta pós-codificados, sendo que as cinco respostas foram somadas para obter uma variável contínua:

3 = associação a conteúdo dentro da família semântica do termo "esquerda". Exemplos: comunismo, socialismo, mudança social, preocupação social, Lula, Fidel Castro.

2 = associação a conteúdo relacionado, de forma distante, com o universo semântico do termo "esquerda". Exemplos: nacionalismo, populismo, povo, radicalismo, oposição.

1 = associação a conteúdo não relacionado com o universo semântico do termo "esquerda". Exemplos: liberalismo, corrupção, adversário, lado torto, contradição.

0 = não resposta, incluindo apenas os indivíduos que não foram capazes de responder a pergunta.
4) Capacidade de associar conteúdos e simbolos cujo conteúdo semântico se aproxima do termo "direita”, independentemente do nível de abstração. Foram também quatro os níveis de resposta pós-codificados, sendo que as cinco respostas foram somadas para obter uma variável contínua:

3 = associação a conteúdo dentro da família semântica do termo "direita". Exemplos: capitalismo, preocupação econômica, desenvolvimento econômico, liberdade econômica, burguesia.

2 = associação a conteúdo relacionado, de forma distante, com o universo semântico do termo "direita". Exemplos: conservação, oposto ao governo atual, ditadura, ordem, democracia.

1 = associação a conteúdo não relacionado com o universo semântico do termo "direita". Exemplos: certo, socialismo, competência, apoio.

0 = não resposta, incluindo apenas os indivíduos que não foram capazes de responder a pergunta.

A Tabela 1 apresenta os resultados da Análise Fatorial por Eixos Principais, que permite averiguar a dimensionalidade entre os oito indicadores (quatro de cada dimensão do conhecimento político) descritos acima. Essa técnica possibilita identificar fatores latentes que representem as relaçōes entre o conjunto das variáveis utilizadas. A técnica identifica as combinaçôes lineares entre as variáveis e fornece uma medida, a carga fatorial, similar a um coeficiente de correlação, que mostra o quanto cada item individual se relaciona com as dimensões latentes. Como se pode observar, tanto é possível aglutinar as variáveis em apenas um construto, como mostra a análise sem rotação, como também é possível separá-las em dois fatores, observando os resultados com a rotação dos fatores (cargas fatoriais superiores a 0,5 são consideradas satisfatórias). ${ }^{9}$ Um matiz importante na análise com a rotação dos fatores é que os itens relacionados com o conhecimento de tipo conceitual também apresentam cargas altas no segundo fator, no qual predominam itens de natureza factual. Esse resultado revela a impossibilidade de se mensurar a capacidade de conceituação sem que se capte, de alguma 
Tabela 1

Análise da Dimensionalidade entre os Itens de Conhecimento Político

\begin{tabular}{lllllll}
\hline & \multicolumn{2}{l}{$\begin{array}{l}\text { Análise Fatorial por } \\
\text { Eixos Principais - Sem } \\
\text { rotação }\end{array}$} & $\begin{array}{l}\text { Análise Fatorial por } \\
\text { Eixos Principais - } \\
\text { Rotação Oblimin }\end{array}$ & Fatores separados \\
\cline { 2 - 7 } & Fator 1 & Fator 2 & Fator 1 & Fator 2 & Informação & Sofisticação \\
\hline Cargos e partidos & 0,618 & 0,450 & 0,436 & 0,764 & 0,764 & - \\
\hline Citaçãa de partidos & 0,628 & 0,478 & 0,437 & 0,789 & 0,792 & - \\
\hline Siglas & 0,599 & 0,475 & 0,411 & 0,764 & 0,763 & - \\
\hline Partidos - ideologia & 0,588 & 0,212 & 0,487 & 0,602 & 0,596 & - \\
\hline Esquerda - abstrato & 0,859 & $-0,319$ & 0,915 & 0,513 & - & 0,915 \\
\hline Esquerda - semântico & 0,866 & $-0,293$ & 0,914 & 0,533 & - & 0,910 \\
\hline Direita - abstrato & 0,835 & $-0,296$ & 0,886 & 0,506 & - & 0,892 \\
\hline Direita - semântico & 0,837 & $-0,255$ & 0,875 & 0,531 & - & 0,873 \\
\hline
\end{tabular}

Fator geral: Alpha de Cronbach = 0,892

Fator de Informação: Alpha de Cronbach = 0,807

Fator de Conceituação: Alpha de Cronbach = 0,939

maneira, a quantidade de informaçóes factuais possuídas. Quando os respondentes são solicitados a associar cinco expressões ao conceito de "esquerda", por exemplo, tais expressões são indicadores não apenas da qualidade das cognições, como também da quantidade de informação de que dispõe sobre a política.

Em suma, as variáveis comportaram-se de modo a compor os fatores da maneira como se esperava. Após a rotação, o primeiro fator corresponde à sofisticação conceitual, ao passo que o segundo representa a posse de informaçôes factuais. Os dois fatores gerados após a rotação foram altamente correlacionados entre si $(r=0,577)$. Sem a rotação, um único fator geral é obtido no qual todas as variáveis apresentam cargas fatoriais altas.

\section{A transmissão de conhecimento factual e conceitual}

Cabe agora averiguar se são os mesmos elementos dos ambientes de socialização política que favorecem tanto a transmissão de informação como a transmissão da habilidade de elaboração conceitual. Em outras palavras, interessa saber se os contextos sociais que estimulam a aquisição de in- formação factual são os mesmos que geram sofisticação conceitual. Como já foi antecipado, espera-se que a sofisticação conceitual dependa de condições específicas e mais exigentes de socialização política. Utilizamos, nos modelos, os escores obtidos a partir das análises fatoriais como nossas variáveis de conhecimento factual e conhecimento conceitual.

Em relação à explicação da aquisição de conhecimento político, dois enquadramentos analíticos principais têm sido utilizados pelos estudiosos. $\mathrm{O}$ primeiro afirma que a aquisição de conhecimento depende de três condições: habilidade, motivação e oportunidade (Luskin, 1990, pp. 334-335; Delli Carpini e Keeter, 1996, p. 179). Habilidade diz respeito às habilidades cognitivas possuídas por uma pessoa para aprender qualquer coisa. Motivação refere-se ao quanto um indivíduo busca se informar e quanta atenção ele dedica às informações disponíveis. Oportunidade, por sua vez, é a disponibilidade de informaçôes sobre determinado assunto.

Apesar da elegância do esquema conceitual que envolve a tríade "habilidade-motivação-oportunidade", não parece haver muita concordância no que diz respeito à determinação das variáveis constitutivas de cada um dos tipos de condição que promovem a aquisição de conhecimento político. 
Tome-se, por exemplo, o caso da principal variável, a saber, os anos de escolaridade do cidadão. Enquanto Luskin (1990) acredita que a escolaridade estaria associada à oportunidade, Delli Carpini e Keeter optam por enquadrar tal variável em um conjunto chamado "estrutural", juntamente com renda e ocupação (1996, p. 180). Estes últimos autores chegam a admitir que as categorias habilidade, motivação e oportunidade dificilmente seriam mutuamente exclusivas, alegando que variáveis como a escolaridade, por exemplo, afetariam tanto a habilidade de aprender sobre política, como dariam mais oportunidade de aprendizado por expor mais o cidadão às informações políticas (Idem, p. 179). Além do mais, essa categorização não parece abarcar conceitualmente algumas variáveis importantes, especialmente aquelas referidas às características da origem familiar dos cidadãos. Revelador disso, por exemplo, é que a variável que indica o interesse político dos pais, utilizada por Luskin (1990, p. 337), não é enquadrada pelo autor em nenhuma das categorias da tríade "habilidade-motivação-oportunidade”. A variável idade também não parece ter lugar bem definido em tal esquema conceitual.

Seja como for, não se trata aqui de descartar o esquema baseado nas condições da habilidade, motivação e oportunidade. No entanto, no caso dos dados do nosso estudo, variáveis típicas aparecem de forma ligeiramente diferenciada. A renda, por exemplo, é um atributo dos pais, e não dos próprios entrevistados. A educação, sendo constante no universo pesquisado, não é uma variável do modelo, mas seu efeito aparece indiretamente por meio do tipo de escola frequentada pelo jovem.

Em suma, para lidar com a especificidade do nosso objeto de estudo, apropriamo-nos de um segundo esquema analítico, próprio de estudos na área da socialização política. Seguimos, aqui, a literatura que vem apresentando evidências de que os ambientes familiar e escolar (Slomczynski e Shabad, 1988; Ichilov, 2007; Finkel e Ernst, 2005) definem, em grande parte, o estoque de conhecimento, os valores e a participação política dos jovens. Estudos recentes (Andolina et al., 2003; Verba, Burns e Scholozman, 2003; Verba, Schlozman e Burns, 2005) na área da socialização política têm chamado a atenção para a influência não só da classe e da escolaridade dos pais, mas também dos modelos de comportamento que o jovem encontra em casa. Especial atenção tem sido dedicada à participação e ao hábito de conversar sobre política. Tais modelos estimulariam ou não o desenvolvimento dos filhos como cidadãos politicamente ativos e informados (Verba, Burns e Scholozman, 2003, pp. 46-47).

Seguindo essa linha de pesquisa, buscamos compreender como os ambientes distintos aos quais os jovens estão expostos ${ }^{10}$ afetam o seu conhecimento sobre política (Niemi e Junn, 1998; Verba, Burns e Scholozman, 2003). Nesse sentido, das três condições já mencionadas, é a "oportunidade" que melhor se enquadra no tema que nos interessa: a desigualdade política proveniente de condiçôes diferenciadas de transmissão do conhecimento político. Afinal, um dos principais fatores que operam na reprodução da desigualdade política é a influência de características da família e da escola sobre as predisposições e conhecimento político dos filhos (Verba, Burns e Scholozman, 2003, p. 46).

Em nosso estudo, as variáveis que representam as diferenças no ambiente familiar dos jovens são as seguintes:

1) Posição de classe do pai: foi perguntado ao entrevistado qual era a ocupação de seu pai. As ocupações foram classificadas em termos de posiçôes de classe. As posiçôes de classe definidas foram as seguintes: trabalhador manual (englobando raros casos de desempregados), trabalhador operacional qualificado, trabalhador administrativo, trabalhador autônomo, gerentes/administradores/ supervisores, profissional/especialista, empresário empregador. A partir dessas sete posiçōes de classe, foi construída uma variável binária que resumisse a linearidade contida entre as variáveis, de modo a obter maior parcimônia no modelo. As posições de classe foram divididas entre posição de elite ou não ( 0 = não elite, incluindo trabalhador manual, trabalhador operacional qualificado, trabalhador administrativo e trabalhador autônomo; 1 = elite, incluindo gerentes/administradores/supervisores, profissional/especialista e empresário empregador). Dos 351 casos, treze apareceram sem resposta, e foram imputados na categoria de referência, ou seja, como "não elite". 
2) Escolaridade dos pais: foi criado um construto a partir da Análise Fatorial por Eixos Principais que aglutinou os anos de escolaridade completos do pai e da mãe do respondente, de modo a obter apenas uma variável geral de escolaridade dos pais. As duas variáveis isoladas foram medidas pelos graus escolares completos ou incompletos do pai e da mãe. Para transformá-las em variáveis contínuas, foi seguida a estratégia de Bills e Haller (1984), atribuindo os seguintes valores para os anos de escolaridade: 0 (nunca freqüentou a escola), 2 ( $1^{\text {a }}$ a $4^{\mathrm{a}}$ série do fundamental incompleto), 4 ( $1^{\mathrm{a}}$ a $4^{\mathrm{a}}$ série do fundamental completo), 6 ( $5^{\mathrm{a}}$ a $8^{\mathrm{a}}$ série do fundamental incompleto), 8 ( $5^{\mathrm{a}}$ a $8^{\mathrm{a}}$ série do fundamental completo), 9,5 ( $1^{\circ}$ ao $3^{\circ}$ do ensino médio incompleto), 11 ( $1^{\circ}$ ao $3^{\circ}$ ano do ensino médio completo), 13 (curso superior incompleto), 15 (curso superior completo), 16 (pós-graduação incompleta) e 17 (pós-graduação completa).

3) Participação política dos pais: foi também criado um construto por Análise Fatorial por Eixos Principais, que aglutinou a participação política do pai e da mãe do respondente. Os índices de participação política do pai e da mãe foram construídos a partir da contagem do número de associações, partidos e sindicatos dos quais os pais dos respondentes participam.

A identificação da escolaridade como principal determinante do conhecimento sobre política constitui, desde Converse (1964), um dos poucos consensos no debate sobre o comportamento político. Mas, os estudos sobre socialização política vem chamando a atenção para a importância de outro fator educacional que afeta a quantidade e a qualidade desse tipo de conhecimento: o ambiente escolar (Niemi e Junn, 1998). Dele fazem parte a concepção curricular, a qualidade e as condiçōes de ensino e os espaços e as oportunidades de participação dentro da escola. Sendo a escolaridade uma constante entre os alunos das escolas que investigamos, o que distingue a educação formal em nossa pesquisa é o ambiente escolar.

Como indicador da diferença entre os ambientes escolares dos jovens, classificamos as escolas em quatro tipos: ${ }^{11}$ escola pública, escola pública militar, escola particular de classe média e escola particular de elite. Foram criadas três variáveis indicado- ras (binárias) a partir das quatro categorias, sendo a primeira (escola pública) a categoria de referência.

Por fim, um terceiro conjunto de variáveis remete a atributos individuais que não dizem respeito diretamente aos ambientes familiar e escolar. Apesar de sua associação com estruturas de oportunidade,$^{12}$ essas variáveis serão, aqui, consideradas atributos do indivíduo, pois, ao contrário da escolaridade ou participação política dos pais, a exposição à informação e o interesse por política só ocorrem quando há iniciativa do jovem.

\section{1) Nivel de interesse por politica do responden-} te: foi perguntado ao respondente o quanto ele se julgava interessado por política. A pergunta continha quatro opçóes de resposta: nada interessado, pouco interessado, interessado e muito interessado. A variável final de interesse por política tornou-se binária, aglutinando as duas primeiras e as duas últimas categorias de respostas $(0=\mathrm{Nada}$ ou pouco interessado; 1 = interessado ou muito interessado).

2) Exposição à informação nos meios de comunicação: foi perguntado com que frequência o jovem consumia informação política em certos meios de comunicação, mais especificamente três tipos: a) TV e rádio; b) jornais e revistas impressos e; c) Internet. Para cada um dos três tipos foi fornecida uma escala com a gradação de exposição $(0=$ Nunca; 1 = Raramente, 2 = Algumas vezes por mês, $3=$ Algumas vezes por semana, $4=$ Diariamente) . $\mathrm{O}$ índice de exposição aos meios de comunicação foi feito a partir do somatório das respostas às três questôes, de modo a constituir uma variável contínua (Alpha de Cronbach = 0,679).

3) Exposição à informação nas conversas do dia a dia: também foi perguntado com que frequência o respondente conversava sobre política com outras pessoas no dia a dia, sendo quatro os tipos: a) conversas com amigos; b) conversas na família; c) atividades na escola e; d) conversas com o professor. Para cada um dos quatro tipos foi fornecida uma escala com a gradação de exposição $(0=$ Nunca; $1=$ Raramente, 2 = Algumas vezes por mês, $3=$ Algumas vezes por semana, 4 = Diariamente). $O$ índice de exposição a conversas foi feito a partir do somatório das respostas às quatro questôes, de modo a constituir uma variável contínua (Alpha de Cronbach =0,723). 
Tabela 2

Variável Dependente: Grau de Conhecimento Factual

\begin{tabular}{|c|c|c|c|c|}
\hline & Modelo 1 & Modelo 2 & Modelo 3 & Modelo 4 \\
\hline & $\begin{array}{l}\text { Coeficiente } \\
\text { (Erro Padrão) } \\
\text { Coeficiente } \\
\text { Padronizado }\end{array}$ & $\begin{array}{l}\text { Coeficiente } \\
\text { (Erro Padrão) } \\
\text { Coeficiente } \\
\text { Padronizado }\end{array}$ & $\begin{array}{l}\text { Coeficiente } \\
\text { (Erro Padrão) } \\
\text { Coeficiente } \\
\text { Padronizado }\end{array}$ & $\begin{array}{l}\text { Coeficiente } \\
\text { (Erro Padrão) } \\
\text { Coeficiente } \\
\text { Padronizado }\end{array}$ \\
\hline Constante & $\begin{array}{l}2,052^{* * *} \\
(0,064)\end{array}$ & $\begin{array}{l}2,292^{* * *} \\
(0,065)\end{array}$ & $\begin{array}{l}1,665^{* * *} \\
(0,129)\end{array}$ & $\begin{array}{l}1,395^{* * *} \\
(0,157)\end{array}$ \\
\hline Posição de classe do pai & $\begin{array}{l}0,568^{\text {*** }} \\
(0,093) \\
0,311\end{array}$ & $\begin{array}{l}0,065 \\
(0,104) \\
0,036\end{array}$ & $\begin{array}{l}0,059 \\
(0,099) \\
0,032\end{array}$ & $\begin{array}{l}-0,065 \\
(0,109) \\
-0,035 \\
\end{array}$ \\
\hline Escolaridade dos pais & & $\begin{array}{l}0,427^{* * *} \\
(0,061) \\
0,411\end{array}$ & $\begin{array}{l}0,351^{\text {*** }} \\
(0,059) \\
0,338\end{array}$ & $\begin{array}{l}0,185^{* *} \\
(0,076) \\
0,178\end{array}$ \\
\hline Participação dos pais & & $\begin{array}{l}0,128^{* * *} \\
(0,046) \\
0,140\end{array}$ & $\begin{array}{l}0,099^{* *} \\
(0,043) \\
0,108 \\
\end{array}$ & $\begin{array}{l}0,106^{* *} \\
(0,043) \\
0,116 \\
\end{array}$ \\
\hline $\begin{array}{l}\text { Exposição à informação nos meios de } \\
\text { comunicação }\end{array}$ & & & $\begin{array}{l}0,086^{* * *} \\
(0,018) \\
0,270\end{array}$ & $\begin{array}{l}0,082^{* * *} \\
(0,018) \\
0,255\end{array}$ \\
\hline Exposição à informação em conversas & & & $\begin{array}{l}-0,010 \\
(0,014) \\
-0,039\end{array}$ & $\begin{array}{l}-0,015 \\
(0,014) \\
-0,060\end{array}$ \\
\hline Interesse & & & $\begin{array}{l}0,195^{*} \\
(0,101) \\
0,101 \\
\end{array}$ & $\begin{array}{l}0,204^{* *} \\
(0,101) \\
0,106 \\
\end{array}$ \\
\hline Tipo de escola $(0=$ pública $)$ & & & & \\
\hline Militar & & & & $\begin{array}{l}0,296^{\text {** }} \\
(0,143) \\
0,146\end{array}$ \\
\hline Particular - classe média & & & & $\begin{array}{l}0,483^{* * *} \\
(0,168) \\
0,232\end{array}$ \\
\hline Particular - elite & & & & $\begin{array}{l}0,682^{* * *} \\
(0,201) \\
0,336\end{array}$ \\
\hline $\mathbf{N}$ & 351 & 351 & 351 & 351 \\
\hline $\mathbf{R}^{2}$ Ajustado & 0,094 & 0,243 & 0,324 & 0,341 \\
\hline Teste F & $37,395^{* * *}$ & $38,550^{* * *}$ & $28,936^{* * *}$ & $21,087^{* * *}$ \\
\hline
\end{tabular}

*** Estatisticamente significativo a 0,01

** Estatisticamente significativo a 0,05

* Estatisticamente significativo a 0,10 
De que forma o ambiente familiar, ambiente escolar e atributos individuais operam na aquisição dos dois tipos de conhecimento político, a posse de informações e a sofisticação conceitual? Desempenhariam, por exemplo, esses dois ambientes papéis distintos na aquisição de conhecimento factual ou de sofisticação conceitual? Algum desses ambientes (a casa ou a escola) teria um impacto mais decisivo na formação de estruturas cognitivas mais complexas, responsáveis pela elaboração de conceitos abstratos? Supomos que, sendo a capacidade de abstração um recurso cognitivo mais exigente e menos comum do que a capacidade de se obter e reter informaçôes, a transmissão da sofisticação conceitual esteja associada a condições sociais específicas.

Os resultados do modelo ajustado para explicar a variação da posse de informaçôes políticas entre os estudantes analisados encontram-se na Tabela 2. Os dados revelam que quase todas as variáveis independentes ${ }^{13}$ se associam de forma relevante ao conhecimento factual.

No ambiente familiar, percebe-se a influência da escolaridade e da participação política, enquanto a classe social não teve efeito relevante, nem estatisticamente significante. Entre as características do indivíduo, a exposição aos meios de comunicação de massa e o interesse por política têm efeitos expressivos, o que indica que, na aquisição de infor- mação política, além das condições, a motivação importa.

Mas, o que chama a atenção é o ambiente escolar. Há um aumento linear e substantivo da média da variável dependente quando se passa da escola pública até chegar à escola particular de elite. Mesmo controlando por uma série de atributos do ambiente familiar e do indivíduo, o tipo de escola permanece sendo a variável com maior potencial explicativo em nosso modelo.

Para a análise da sofisticação conceitual, os testes demandaram alguns artifícios metodológicos. Isso porque 145 jovens não foram capazes de apresentar nenhuma expressão como resposta às perguntas sobre os termos "direita" e "esquerda", tornando a distribuição da variável dependente acentuadamente assimétrica (Gráfico 1).

$\mathrm{O}$ artifício que utilizamos para averiguar os efeitos das variáveis independentes sobre a sofisticação conceitual dos jovens foi transformar a variável original em duas variáveis novas. A primeira delas passou a ser binária, na qual os 145 indivíduos com o escore mínimo no construto original receberam valor 0 e os demais, valor 1 . A segunda foi construída excluindo os jovens que obtiveram o escore mínimo na variável original e utilizando o logaritmo natural (ln) da variável original para os demais, aproximando a distribuição da variável dependente da distribuição normal.

Gráfico 1

Distribuição da sofisticação conceitual

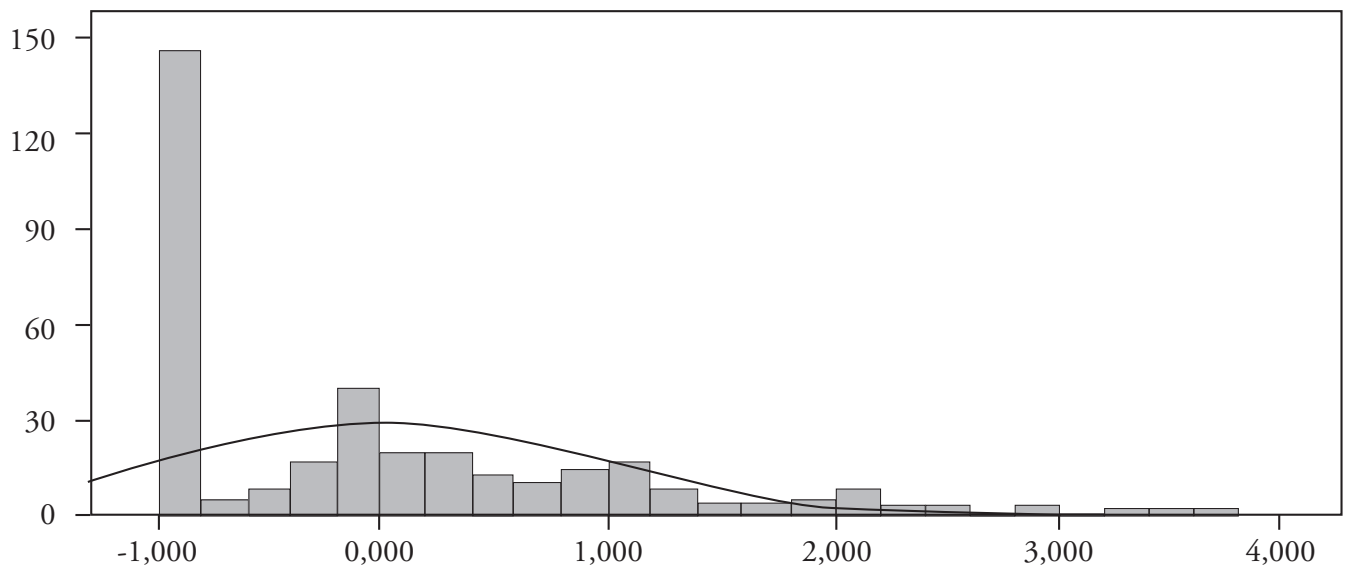

Sofisticação conceitual 
Tabela 3

Variável Dependente: Grau de Conhecimento Conceitual (Binária)

\begin{tabular}{|c|c|c|c|c|}
\hline & Modelo 1 & Modelo 2 & Modelo 3 & Modelo 4 \\
\hline & $\begin{array}{l}\text { Coeficiente } \\
\text { (Erro Padrão) } \\
\text { Efeito } \\
\text { Percentual }\end{array}$ & $\begin{array}{l}\text { Coeficiente } \\
\text { (Erro Padrão) } \\
\text { Efeito } \\
\text { Percentual }\end{array}$ & $\begin{array}{l}\text { Coeficiente } \\
\text { (Erro Padrão) } \\
\text { Efeito } \\
\text { Percentual }\end{array}$ & $\begin{array}{l}\text { Coeficiente } \\
\text { (Erro Padrão) } \\
\text { Efeito } \\
\text { Percentual }\end{array}$ \\
\hline Constante & $\begin{array}{l}-0,240 \\
(0,149) \\
-11,4 \% \\
\end{array}$ & $\begin{array}{l}0,118 \\
(0.172) \\
12,5 \%\end{array}$ & $\begin{array}{l}-1,073^{* * *} \\
(0,390) \\
-75,8 \%\end{array}$ & $\begin{array}{l}-2,043^{* * *} \\
(0,515) \\
-87 \%\end{array}$ \\
\hline Posição de classe do pai & $\begin{array}{l}1,331^{* * *} \\
(0,232) \\
278,5 \%\end{array}$ & $\begin{array}{l}0,642^{* *} \\
(0,278) \\
90.0 \%\end{array}$ & $\begin{array}{l}0,689^{* *} \\
(0,289) \\
99,1 \%\end{array}$ & $\begin{array}{l}0,314 \\
(0,323) \\
36,9 \% \\
\end{array}$ \\
\hline Escolaridade dos pais & & $\begin{array}{l}0,595^{\text {*** }} \\
(0,170) \\
81,2 \%\end{array}$ & $\begin{array}{l}0,468^{* * *} \\
(0,178) \\
59,7 \%\end{array}$ & $\begin{array}{l}-0,092 \\
(0,231) \\
-8,8 \% \\
\end{array}$ \\
\hline Participação dos pais & & $\begin{array}{l}0,352^{* *} \\
(0,141) \\
42,2 \%\end{array}$ & $\begin{array}{l}0,311^{* *} \\
(0,146) \\
36,5 \%\end{array}$ & $\begin{array}{l}0,353^{* *} \\
(0,149) \\
42,4 \% \\
\end{array}$ \\
\hline $\begin{array}{l}\text { Exposição à informação nos meios de } \\
\text { comunicação }\end{array}$ & & & $\begin{array}{l}0,023 \\
(0,052) \\
2,3 \% \\
\end{array}$ & $\begin{array}{l}0,008 \\
(0,054) \\
0,08 \% \\
\end{array}$ \\
\hline Exposição à informação em conversas & & & $\begin{array}{l}0,110^{* * *} \\
(0,042) \\
11,6 \%\end{array}$ & $\begin{array}{l}0,097^{* *} \\
(0,044) \\
10,2 \%\end{array}$ \\
\hline Interesse & & & $\begin{array}{l}0,170 \\
(0,290) \\
18,6 \% \\
\end{array}$ & $\begin{array}{l}0,200 \\
(0,300) \\
22,2 \% \\
\end{array}$ \\
\hline \multicolumn{5}{|l|}{ Tipo de escola $(0=$ pública $)$} \\
\hline Militar & & & & $\begin{array}{l}0,998^{* *} \\
(0,439) \\
71,2 \%\end{array}$ \\
\hline Particular - classe média & & & & $\begin{array}{l}1,552^{* * *} \\
(0,513) \\
372,2 \%\end{array}$ \\
\hline Particular - elite & & & & $\begin{array}{l}2,337^{* * *} \\
(0,629) \\
935,2 \%\end{array}$ \\
\hline $\mathbf{N}$ & 351 & 351 & 351 & 351 \\
\hline Nagelkerke $\mathbf{R}^{2}$ & 0,128 & 0,212 & 0,254 & 0,303 \\
\hline Proporção de acertos do modelo & $65,0 \%$ & $68,9 \%$ & $70,4 \%$ & $72,6 \%$ \\
\hline Qui-quadrado & $35,125 \%$ & $60,108^{* * *}$ & $74,634^{* * *}$ & $89,583^{* * *}$ \\
\hline
\end{tabular}

*** Estatisticamente significativo a 0,01

** Estatisticamente significativo a 0,05

* Estatisticamente significativo a 0,10 
Dessa forma, um modelo de regressão logística binária foi ajustado para toda a amostra de modo a possibilitar o exame sobre quais variáveis explicariam a passagem do escore mínimo para os demais valores, isto é, o que faria um respondente dar alguma resposta nas perguntas que medem sofisticação conceitual. Um modelo linear também foi ajustado para elucidar a variação do conhecimento conceitual apenas entre os que obtiveram um valor acima do mínimo. ${ }^{14}$

As Tabelas 3 e 4 mostram os resultados do modelo logístico binário e da regressão linear, respectivamente.

No exame da Tabela 3, destacam-se alguns dados. No ambiente familiar, a participação dos pais é a única variável relevante para distinguir os jovens que responderam a questão sobre conhecimento conceitual. A posição de classe do pai, seguindo o mesmo padrão do conhecimento factual, perde seu efeito quando são incluídas novas variáveis na análise. A novidade é que a escolaridade dos pais também perde o seu poder explicativo quando controlado pelo ambiente escolar. Outra diferença em relação ao modelo que explica a posse de informação factual é o efeito da exposição aos meios de informação. Enquanto a freqüência do uso dos meios de comunicação está intimamente associada à posse de informação factual, é o hábito de conversar sobre política que conta na formação de jovens politicamente sofisticados.

Padrões semelhantes aos que vemos na Tabela 3 são observados na tabela 4 , que mostra os resultados do modelo de regressão linear ajustado tendo como variável dependente o construto de conhecimento conceitual normalizado. Pelas razôes explicitadas acima, na Tabela 4 constam apenas os indivíduos que associaram, ao menos, uma expressão aos termos esquerda e direita.

O ambiente escolar, mais uma vez, é o melhor preditor da habilidade de que dispõe o jovem para elaborar conhecimento político do tipo conceitual. Apesar de não haver diferença estatisticamente significativa entre as escolas militares e as escolas públicas, o coeficiente que expressa a diferença entre escolas públicas e escolas privadas é bastante alto. ${ }^{15}$

O efeito da posição de classe do pai desaparece, de início, com a inclusão das demais variáveis do ambiente familiar (modelo 2), o que difere da tabela 3. Já a escolaridade dos pais mantém o padrão desta tabela, perdendo o seu efeito quando é controlado pelo tipo de escola. Novamente, entre as variáveis do ambiente familiar, a participação dos pais é a única que contribui para a explicação da transmissão intergeracional do pensamento conceitual.

A diferença entre exposição à informação nas conversas e nos meios de comunicação de massa segue a mesma direção da Tabela 3, ainda que os coeficientes não sejam estatisticamente significativos. Este último resultado convida a elaborar uma análise mais substantiva do conjunto de evidências apresentadas. Primeiro, percebe-se que o conhecimento conceitual não é impulsionado, como no caso da informação política, apenas pela exposição "passiva" aos jornais, à Internet ou à TV. O diálogo e a exposição rotineira ao debate político são fatores imprescindíveis na formação de jovens com habilidade de pensar na política a partir de conceitos abstratos.

Isso não nos surpreende, pois o acompanhamento de notícias nos jornais e, especialmente, na televisão nos trazem mais "fatos" do que uma elaboração conceitual sobre o mundo da política, enquanto os ambientes em que se conversa com frequência sobre a política, em especial aqueles politicamente ativos, nos colocam em contato com a dinâmica de elaboração de argumentos políticos.

Estudos recentes (Andolina et al., 2003; Verba, Schlozman e Burns, 2003) têm chamado a atenção para a influência dos modelos de comportamento que o jovem encontra em casa, em especial a participação política e a conversa sobre a política. Nossos dados permitem acrescentar que, além de conversar e participar mais de atividades políticas, esses jovens têm também mais capacidade de elaborar conceitos quando pensam sobre política.

Ao considerar as diferenças entre os fatores que explicam a aquisição dos dois tipos de conhecimento, percebemos que, enquanto pais participativos estimulam tanto a aquisição de conhecimento factual como de conhecimento conceitual, pais com alta escolaridade transmitem apenas informação, mas não a habilidade de pensar conceitualmente a política. 
Tabela 4

Variável Dependente: Grau de Conhecimento Conceitual

\begin{tabular}{|c|c|c|c|c|}
\hline & Modelo 1 & Modelo 2 & Modelo 3 & Modelo 4 \\
\hline & $\begin{array}{l}\text { Coeficiente } \\
\text { (Erro Padrão) } \\
\text { Coeficiente } \\
\text { Padronizado }\end{array}$ & $\begin{array}{l}\text { Coeficiente } \\
\text { (Erro Padrão) } \\
\text { Coeficiente } \\
\text { Padronizado }\end{array}$ & $\begin{array}{l}\text { Coeficiente } \\
\text { (Erro Padrão) } \\
\text { Coeficiente } \\
\text { Padronizado }\end{array}$ & $\begin{array}{l}\text { Coeficiente } \\
\text { (Erro Padrão) } \\
\text { Coeficiente } \\
\text { Padronizado }\end{array}$ \\
\hline Constante & $\begin{array}{l}3,023^{* * *} \\
(0,070)\end{array}$ & $\begin{array}{l}3,095^{* * *} \\
(0,069)\end{array}$ & $\begin{array}{l}2,803^{\text {*** }} \\
(0,147)\end{array}$ & $\begin{array}{l}2,446^{* * *} \\
(0,217)\end{array}$ \\
\hline Posição de classe do pai & $\begin{array}{l}0,374^{* * * *} \\
(0,089) \\
0,281 \\
\end{array}$ & $\begin{array}{l}0,119 \\
(0,103) \\
0,090 \\
\end{array}$ & $\begin{array}{l}0,113 \\
(0,103) \\
0,085 \\
\end{array}$ & $\begin{array}{l}-0,009 \\
(0,109) \\
-0,007 \\
\end{array}$ \\
\hline Escolaridade dos pais & & $\begin{array}{l}0,228^{* * *} \\
(0,068) \\
0,269\end{array}$ & $\begin{array}{l}0,204^{* * *} \\
(0,069) \\
0,241\end{array}$ & $\begin{array}{l}0,050 \\
(0,084) \\
0,059 \\
\end{array}$ \\
\hline Participação dos pais & & $\begin{array}{l}0,106^{* *} \\
(0,043) \\
0,169 \\
\end{array}$ & $\begin{array}{l}0,101^{\text {** }} \\
(0,042) \\
0,160 \\
\end{array}$ & $\begin{array}{l}0,107^{* *} \\
(0,042) \\
0,170 \\
\end{array}$ \\
\hline $\begin{array}{l}\text { Exposição à informação nos meios de } \\
\text { comunicação }\end{array}$ & & & $\begin{array}{l}-0,001 \\
(0,019) \\
-0,003 \\
\end{array}$ & $\begin{array}{l}-0,002 \\
(0,019) \\
-0,010 \\
\end{array}$ \\
\hline Exposição à informação em conversas & & & $\begin{array}{l}0,027^{*} \\
(0,015) \\
0,138\end{array}$ & $\begin{array}{l}0,023 \\
(0,015) \\
0,119 \\
\end{array}$ \\
\hline Interesse & & & $\begin{array}{l}0,081 \\
(0,114) \\
0,054 \\
\end{array}$ & $\begin{array}{l}0,110 \\
(0,113) \\
0,072 \\
\end{array}$ \\
\hline Tipo de escola $(0=$ pública $)$ & & & & \\
\hline Militar & & & & $\begin{array}{l}0,281 \\
(0,199) \\
0,183 \\
\end{array}$ \\
\hline Particular - classe média & & & & $\begin{array}{l}0,523^{* *} \\
(0,211) \\
0,368 \\
\end{array}$ \\
\hline Particular - elite & & & & $\begin{array}{l}0,685^{\text {*** }} \\
(0,241) \\
0,517\end{array}$ \\
\hline $\mathbf{N}$ & 206 & 206 & 206 & 206 \\
\hline R2 Ajustado & 0,075 & 0,161 & 0,175 & 0,205 \\
\hline Teste F & $17,556^{* * *}$ & $14,101^{* * *}$ & $8,247^{* * *}$ & $6,890^{* * *}$ \\
\hline
\end{tabular}

*** Estatisticamente significativo a 0,01

** Estatisticamente significativo a 0,05

* Estatisticamente significativo a 0,10 
Esta última observação remete ao grande desafio da nossa análise: entender por que os dois fatores socioeconômicos que são tidos como os de maior poder preditivo sobre a cognição política - a escolaridade e a classe social - têm um papel discreto em nossos modelos de conhecimento conceitual e mesmo, no caso da classe, nos modelos de conhecimento factual. A interpretação que propomos para explicar esse (aparente) "divórcio" entre, de um lado, a escolaridade e a posição de classe dos pais e, de outro, o conhecimento conceitual dos filhos passa pela noção de efeito indireto.

Seguindo essa linha de interpretação, devemos lembrar que, no caso do conhecimento conceitual (Tabela 3), a escolaridade dos pais e a posição de classe perdem poder explicativo apenas quando o tipo de escola entra no modelo. Isso sugere que se, de um lado, pais com escolaridade e/ou condição econômica elevadas não transmitem habilidade conceitual aos filhos, de outro, as portas das escolas que desempenham bem esse papel se abrem com muito mais facilidade para esses estratos socioeconômicos.

Visto de outro ângulo, pode-se dizer que não basta que os pais tenham alta escolaridade ou renda para que os filhos alcancem uma apreensão conceitual do universo da política. A escolha do ambiente escolar adequado é o fator crucial na transmissão da capacidade de elaborar conceitualmente as informaçōes políticas.

Há, então, duas dinâmicas complementares entre escolaridade dos pais, posição de classe do pai e tipo de escola, na sua relação com o conhecimento político. Na primeira delas, a classe exerce efeitos indiretos, "empurrando", para cima ou para baixo, a escolaridade dos pais, a qual, além de ter impacto seletivo sobre o tipo de escola que o jovem vai freqüentar, também atua, de forma direta, no processo mediante o qual o jovem se torna bem ou mal informado em matéria de política. Em relação ao conhecimento conceitual, outro padrão é mais visível. Nele, tanto a classe como a escolaridade dos pais só "agem" como constrangimentos ou recursos capazes de influenciar a escolha da escola dos filhos.

Para visualizarmos, no conjunto, as diferenças entre os determinantes da aquisição dos dois tipos de conhecimento, apresentamos, nas Figuras 1 e 2, o quadro mais completo das duas dinâmicas que conduzem ao conhecimento sobre política, incluindo agora os demais elementos do ambiente familiar e as características individuais. ${ }^{16}$

Ainda falta comentar o fato de o interesse por política pouco contribuir, em nossos modelos, para a compreensão dos processos mediante os quais se adquire conhecimento político. $\mathrm{O}$ interesse sobre política tem efeito muito menor do que o esperado no modelo que explica a aquisição do conhecimento factual sobre política. Já no modelo ajustado para analisar a aquisição do conhecimento conceitual, ele perde completamente seu poder explicativo. Parece, então, que os dados de nossa pesquisa desafiam um dos poucos consensos entre os estudiosos do comportamento político: o de que o interesse por política, juntamente com a escolaridade, explica o conhecimento político.

Nosso entendimento é de que o interesse não deixou, de uma hora para outra, de explicar o conhecimento sobre política ou que essa tese não se aplique ao nosso objeto de estudo. Supomos que o efeito do interesse tenha sido "capturado" pelas variáveis sobre exposição à informação política, as quais medem fenômenos da mesma natureza. As correlações elevadas entre o interesse e as duas variáveis de exposição à informação ${ }^{17}$ reforçam a nossa suspeita. ${ }^{18}$ Sendo assim, a exposição à informação política nos meios de comunicação e em conversas seriam proxies de uma modalidade mais exigente de interesse por política, o qual, nesse sentido, permanece sendo um fator importante para explicar o conhecimento político.

Esse panorama dos padrôes de aquisição dos dois tipos de conhecimento é, no nosso entendimento, suficientemente persuasivo quanto aos ganhos analíticos proporcionados pela distinção entre eles. Ainda assim, como mostramos na segunda seção deste artigo, é possível aglutinar os itens utilizados para unificar os dois tipos de conhecimento político em apenas um construto. Concluiremos, então, a nossa análise com uma breve consideração a respeito do construto mais geral de conhecimento político.

A Tabela 5 apresenta os dados do modelo de regressão linear tendo como variável dependente o "conhecimento político". 


\section{Figura 1}

\section{Dinâmica de Aquisiçáo de Conhecimento Factual}

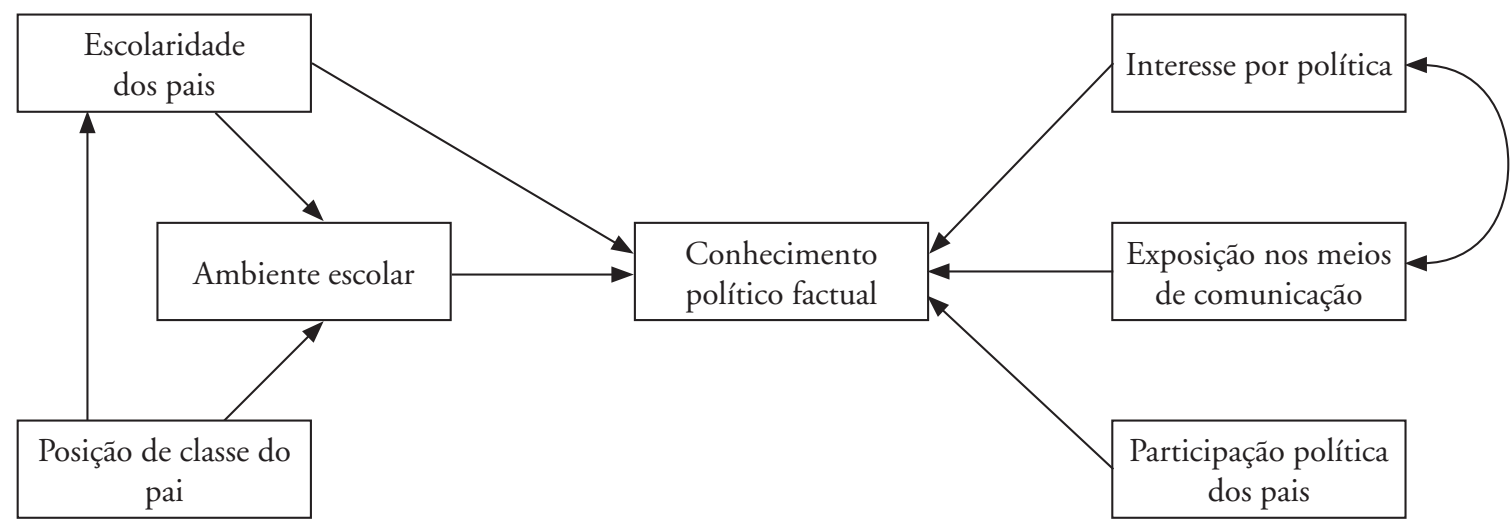

Figura 2

\section{Dinâmica de Aquisição de Conhecimento Conceitual}

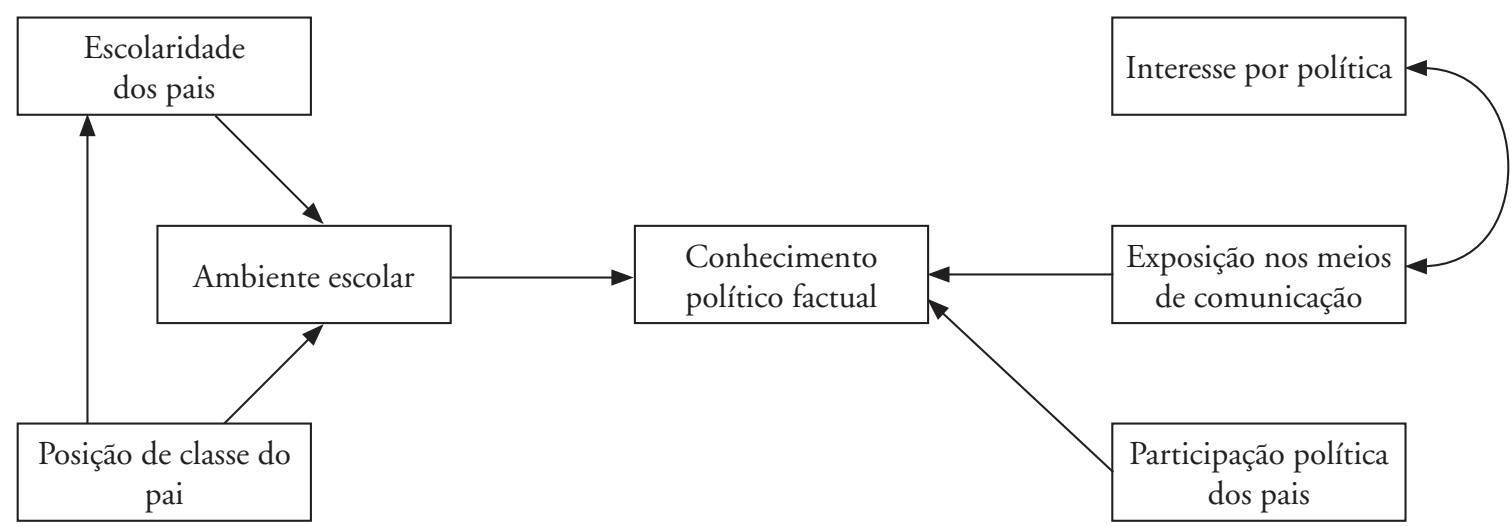

Os principais resultados da Tabela 5 são um resumo agregado dos resultados dos modelos anteriores. No ambiente familiar, se considerarmos apenas os efeitos diretos, a participação política dos pais é o único fator responsável pela aquisição de conhecimento político. O contexto escolar é, mais uma vez, marcado pela nítida diferença entre as escolas públicas e privadas. Por fim, reunindo os determinantes dos dois tipos de conhecimento, as duas variáveis de exposição à informação agem de forma moderada sobre a aquisição de conhecimento polí- tico. Em suma, os resultados atestam a validade da medida mais geral de conhecimento político, mas, ao mesmo tempo, mostram a sua limitação, pois ele não permite distinguir as especificidades e, em especial, os mecanismos de transmissão social dos dois tipos de conhecimento.

Retomando nossa pergunta inicial e, ao mesmo tempo, um tema central desse artigo, o conjunto da análise aponta numa só direção: os alunos cujos pais são mais escolarizados e participam mais de atividades de natureza política, os 
Tabela 5

Variável Dependente: Grau de Conhecimento Político

\begin{tabular}{|c|c|c|c|c|}
\hline & Modelo 1 & Modelo 2 & Modelo 3 & Modelo 4 \\
\hline & $\begin{array}{l}\text { Coeficiente } \\
\text { (Erro Padrão) } \\
\text { Coeficiente } \\
\text { Padronizado }\end{array}$ & $\begin{array}{l}\text { Coeficiente } \\
\text { (Erro Padrão) } \\
\text { Coeficiente } \\
\text { Padronizado }\end{array}$ & $\begin{array}{l}\text { Coeficiente } \\
\text { (Erro Padrão) } \\
\text { Coeficiente } \\
\text { Padronizado }\end{array}$ & $\begin{array}{l}\text { Coeficiente } \\
\text { (Erro Padrão) } \\
\text { Coeficiente } \\
\text { Padronizado }\end{array}$ \\
\hline Constante & $\begin{array}{l}1,072^{* * *} \\
(0,066)\end{array}$ & $\begin{array}{l}1,313^{* * *} \\
(0,066)\end{array}$ & $\begin{array}{l}0,710^{* * *} \\
(0,134)\end{array}$ & $\begin{array}{l}0,422^{* * *} \\
(0,160)\end{array}$ \\
\hline Posição de classe do pai & $\begin{array}{l}0,771^{\text {*** }} \\
(0,095) \\
0,397\end{array}$ & $\begin{array}{l}0,264^{* *} \\
(0,106) \\
0,136\end{array}$ & $\begin{array}{l}0,264^{* *} \\
(0,103) \\
0,136\end{array}$ & $\begin{array}{l}0,058 \\
(0,111) \\
0,030\end{array}$ \\
\hline Escolaridade dos pais & & $\begin{array}{l}0,377^{* * *} \\
(0,062) \\
0,341\end{array}$ & $\begin{array}{l}0,301^{* * *} \\
(0,062) \\
0,272\end{array}$ & $\begin{array}{l}0,091 \\
(0,078) \\
0,082\end{array}$ \\
\hline Participação dos pais & & $\begin{array}{l}0,227^{* * *} \\
(0,046) \\
0,234\end{array}$ & $\begin{array}{l}0,198^{* * *} \\
(0,045) \\
0,204\end{array}$ & $\begin{array}{l}0,203^{* * *} \\
(0,044) \\
0,208\end{array}$ \\
\hline $\begin{array}{l}\text { Exposição à informação nos meios de } \\
\text { comunicação }\end{array}$ & & & $\begin{array}{l}0,035^{*} \\
(0,018) \\
0,104\end{array}$ & $\begin{array}{l}0,031^{*} \\
(0,018) \\
0,093\end{array}$ \\
\hline Exposição à informação em conversas & & & $\begin{array}{l}0,030^{* *} \\
(0,015) \\
0,111 \\
\end{array}$ & $\begin{array}{l}0,024^{*} \\
(0,014) \\
0,089 \\
\end{array}$ \\
\hline Interesse & & & $\begin{array}{l}0,174^{*} \\
(0,105) \\
0,085\end{array}$ & $\begin{array}{l}0,178^{*} \\
(0,103) \\
0,087\end{array}$ \\
\hline Tipo de escola $(0=$ pública $)$ & & & & \\
\hline Militar & & & & $\begin{array}{l}0,234 \\
(0,146) \\
0,108\end{array}$ \\
\hline Particular - classe média & & & & $\begin{array}{l}0,538^{* * *} \\
(0,172) \\
0,243 \\
\end{array}$ \\
\hline Particular - elite & & & & $\begin{array}{l}0,895^{\text {*** }} \\
(0,206) \\
0,415\end{array}$ \\
\hline $\mathbf{N}$ & 351 & 351 & 351 & 351 \\
\hline R2 Ajustado & 0,155 & 0,310 & 0,358 & 0,393 \\
\hline Teste F & $65,157^{* * *}$ & $53,497^{* * *}$ & $33,478^{* * *}$ & $26,159^{* * *}$ \\
\hline
\end{tabular}

*** Estatisticamente significativo a 0.01

** Estatisticamente significativo a 0.05

* Estatisticamente significativo a 0.10 
que estudam em colégios de elite e os que estão mais expostos à informação política superam os demais quanto à posse de recursos cognitivos. Se considerarmos o poderoso efeito indireto da classe social, esse quadro aponta para um cenário pouco otimista: a tendência à reprodução da desigualdade política. Isso porque o conhecimento político proporciona aos indivíduos maior clareza quanto às suas preferências e estimula a participação, mediante a qual tais preferências influenciam o processo político.

\section{Considerações finais}

As conclusões gerais a serem extraídas das análises aqui realizadas já foram antecipadas. ${ }^{19}$ Em primeiro lugar, o exame dos dados a partir das análises fatoriais permitiu verificar que tanto se pode distinguir a posse de informaçôes factuais e a sofisticação conceitual como dois construtos distintos, como é possível os tratar como parte de um construto latente mais geral, o do conhecimento político.

Diferentemente de alguns analistas que afirmam que a informação sobre política seria representativa do conhecimento político, em geral, especialmente em virtude da confiabilidade de sua mensuração, nossas análises permitem esclarecer aspectos importantes no que se refere à diferença entre as duas dimensões clássicas do conhecimento político.

O domínio de um grande volume de informação quanto a partidos, pessoas e eventos da política dependem do acesso aos meios de comunicação convencionais e da escolaridade dos pais. Mas, nossa análise mostrou que a exposição, mais ou menos passiva, às mensagens veiculadas pelos meios de comunicação não é o suficiente para o desenvolvimento da capacidade de elaborar conceitualmente as informaçôes sobre o mundo político.

O diferencial do ambiente informacional que confere aos jovens a capacidade de articular conceitualmente o seu entendimento sobre política é a participação no dia a dia em conversas sobre política. A valorização da política como espaço de engajamento intelectual e comportamental, na es- fera doméstica e suas redes, é elemento distintivo do ambiente familiar em que é socializado o jovem que tem refinamento político.

Acima de tudo, nosso estudo não deixa dúvidas de que o tipo de escola determina as chances que o jovem tem de desenvolver as habilidades cognitivas de natureza política. Ser socializado numa família formada por pais escolarizados e interessados e ativos, na política, e com acesso frequente aos meios de comunicação certamente estimula a ampliação do conhecimento sobre política. Mas, esses efeitos do ambiente familiar serão moderados se o jovem não frequentar as escolas mais bem servidas pelos recursos que permitem acesso à informação política e que estimulem o interesse por política.

Em conjunto, essas considerações conduzem à conclusão de que os padrôes de transmissão dos dois tipos de conhecimento atuam como mecanismos de reprodução de um tipo específico de estratificação social: a estratificação cognitiva. Pertencer a classes sociais mais altas e escolarizadas, estudar em escola de elite, ter acesso aos meios de comunicação e estar inserido em um ambiente familiar politicamente estimulante são os ingredientes que "empurram" os jovens para o estrato superior da divisão cognitiva da sociedade. São esses jovens que podem se candidatar a uma vaga no seleto clube que a escola de Michigan chamou de "ideólogos" (Campbell et al., 1960, p. 227; Converse, 1964, pp. 215-216).

Um passo importante no que se refere à distinção entre os dois tipos de conhecimento político seria, a partir daqui, tomar tais variáveis como fatores explicativos de comportamentos. Nesse sentido, caberia considerar em que medida a diferenciação e a integração se distinguiriam não pelos processos que as causariam, mas antes pelos diferentes tipos de comportamento político que elas engendrariam. Se as análises e as conclusões apresentadas no presente artigo estiverem corretas, um caminho interessante de pesquisa seria, portanto, a investigação sobre o efeito diferenciado de cada uma das duas dimensões do conhecimento sobre fenômenos relevantes para os estudiosos de opiniāo pública. 


\section{Notas}

1 No Brasil, esse tema tem sido abordado por alguns autores. Ver Reis e Castro (1992), Castro (1994) e Rennó (2007).

2 No Brasil, outros estudos sobre juventude e comportamento político adotaram enfoques diferentes do nosso. Abramo e Venturi (2000), por exemplo, procuraram fazer um diagnóstico mais amplo sobre a juventude brasileira, cobrindo aspectos culturais, políticos e econômicos. Outros trabalhos analisaram as visões dos jovens sobre a política institucional (Nazzari, 2007; Castro, 2008; Florentino, 2008). Já o trabalho de Baquero e Baquero (2007) discute a participação política dos jovens, além de enfatizar o papel da educação no processo de socialização política. O relatório de pesquisa de dados nacionais realizado pelo Ibase, em parceria com o Instituto Polis (2005), apresenta uma análise sobre diversos aspectos da participação política dos jovens no Brasil.

3 De acordo com esses autores, esta não exigiria consistência entre as diversas atitudes políticas adotadas pelo indivíduo.

4 O uso de medidas de sofisticação política em estudos brasileiros também se caracteriza pela utilização de questões de informações factuais (Reis e Castro, 1992). O estudo de Rennó (2007), além das questões de informação factual, incluiu também medidas de "opinação" (quantidade de opiniões omitidas pelo respondente). Já Castro (1994) incorporou medidas de interesse e exposição à informação ao seu construto de sofisticação política, seguindo Neuman (1986).

5 A pesquisa seguiu um desenho quase experimental com pré-teste e pós-teste e grupo de controle, sem randomização, porém com emparelhamento. A randomização não poderá ser feita, em função da natureza do estudo, pois a escolha dos indivíduos que participam do Parlamento Jovem está fora do controle dos pesquisadores e não segue critérios aleatórios. $\mathrm{O}$ emparelhamento entre o grupo de tratamento e o grupo de controle foi feito por meio da seleção de estudantes de outras escolas que não participaram do Parlamento Jovem, com base em certas características importantes como, por exemplo, se eram públicas ou privadas e o valor das mensalidades nas escolas privadas. Ao todo, jovens de catorze escolas foram entrevistados. Houve dois momentos de mensuração: a) o primeiro ocorreu no início do Parlamento Jovem; e b) o segundo, ao final do projeto. Apenas os dados da primeira onda de entrevistas, a qual antecede a experiência de participar no Parlamento Jovem, serão explorados aqui.

6 O Parlamento Jovem é desenvolvido pela Escola do Legislativo, vinculada à Assembleia Legislativa de Minas Gerais, em parceria com o curso de Ciências Sociais da Pontifícia Universidade Católica (PUC-Minas) e é destinado aos alunos do ensino médio das escolas das redes pública e privada de Belo Horizonte. Suas atividades desenvolvem-se durante um semestre, concentradas em três dimensões: de formação política, de capacitação e de participação no Parlamento.

7 A classificação dos partidos entre esquerda (PT, PSTU e PC do B) e direita (PP e DEM) foi feita com base em Power e Zucco (2009).

8 As duas perguntas foram feitas da seguinte maneira: "Quando o assunto é política, quais seriam as palavras ou expressões que, para você, definem o termo esquerda/direita?". Na medida em que o respondente fornecia respostas, o entrevistador aplicava o seguinte probe: "Que outra palavra ou expressão você poderia me dizer?".

9 Optamos por utilizar a rotação oblíqua, em oposição à rotação ortogonal, uma vez que supomos que as duas dimensões do conhecimento político, ainda que analiticamente distintas, estão correlacionadas. A rotação ortogonal gera fatores que não possuem correlação, o que viola uma suposição teórica fundamental em nossa análise (Costello e Osborne, 2005).

10 Evidentemente, além dos ambientes, outros atributos propriamente individuais, como a exposição à informação política e o interesse por política, compóem o modelo explicativo, mas a ênfase consiste em avaliar os efeitos do ambiente familiar e do ambiente escolar sobre o conhecimento político do aluno. Além disso, variáveis próprias do indivíduo ocupariam um lugar intermediário na explicação, tendo em vista que seriam elas mesmas condicionadas pelos ambientes. Nesse sentido, variáveis referidas a ambientes e a atributos e predisposições individuais seriam menos concorrentes na aquisição do conhecimento político, e antes complementares entre si no esquema analítico.

11 Os critérios utilizados na classificação das escolas como de elite e classe média foram a mensalidade e a localização geográfica. Assim, nenhuma escola de classe média tem, na primeira e segunda série do ensino médio, mensalidade superior a R \$ 520,00, enquanto as mensalidades das escolas de elite variam entre $\mathrm{R} \$$ 642,00 e 738.00. Da mesma forma, além de serem reconhecidas publicamente como "tradicionais", todas as escolas de elite se situam na região mais valoriza- 
da de Belo Horizonte (zona sul). No caso das escolas públicas e militares, a classificação apenas reproduz a identidade jurídica dessas escolas.

12 Por exemplo, o jovem que tem, em sua casa, a assinatura de um jornal de circulação nacional encontra melhores condições de acesso aos meios de informação política do que aquele que não tem.

13 Uma análise similar foi feita tendo como variáveis de controle o sexo e a raça dos respondentes. Como os padrões de resultados para as variáveis de interesse teórico do trabalho foram muito parecidos nos modelos com e sem esses controles estatísticos, optamos por apresentar um modelo sem eles.

14 Desse modo, modelamos a probabilidade $\operatorname{Pr}[y=0 / x]$ como um logit e o $\log (\mathrm{y}) / \mathrm{y}, \mathrm{x}>0$ como uma normal. Como resultado, temos dois tipos de coeficientes diferentes para cada modelo. No modelo que tem como dependente $\mathrm{o}$ indicador de $\mathrm{y}>0$, obtemos a probabilidade de sair do valor $\mathrm{y}=0$. Já no modelo de mínimos quadrados ordinários para a regressão de $\log (\mathrm{y}) \mathrm{em} \mathrm{x}$, usando as observaçôes para as quais $y>0$, o coeficiente é o beta dos modelos lineares.

15 Um aluno de escola privada de elite possui, em média, 0,685 pontos a mais no escore que vai de 0,8 a, aproximadamente, 4,5 do que o aluno da escola pública.

16 Não foi possível utilizar os modelos de análise de trajetória para explorar a dinâmica dos efeitos indiretos, tal como apresentada nos diagramas. As variáveis endógenas nos modelos de equaçōes estruturais devem ser contínuas, mas as nossas variáveis do ambiente escolar são binárias.

$17 \mathrm{O} r$ de Pearson foi de 0,442 com a de exposição aos meios de comunicação, e de 0,450 , com a de exposição às conversas.

18 Nos modelos que apresentamos até aqui, o espaço das tabelas não permitiu a inserção de um modelo intermediário no qual o interesse por política era inserido em um passo anterior às variáveis de exposição à informação. No modelo linear, que explica a aquisição de conhecimento factual, o coeficiente padronizado cai de 0,180 para 0,106 com a inserção das variáveis de exposição à informação. Já no modelo logístico, que explica a aquisição de conhecimento conceitual, o efeito percentual do interesse cai de $66,2 \%$ para $22,2 \%$, e deixa de ser estatisticamente significativo.

19 Vale assinalar que tais resultados não podem ser inferidos para a população dos jovens secundaristas de Belo Horizonte porque a amostra utilizada não foi aleatória.

\section{BIBLIOGRAFIA}

VENTURI, Gustavo \& ABRAMO, Helena (2000), "Juventude, política e cultura". Revista Teoria em Debate, 45: 28-33, jul.-ago.-set.

ANDOLINA, Molly; JENKINS, Krista; ZUKIN, Cliff \& KEETER, Scott. (2003), "Habits from home, lessons from school: influences on youth civic engagement". Political Science and Politics, 36 (2): 275-280.

BAQUERO, Rute \& BAQUERO, Marcello. (2007), "Educando para a democracia: valores democráticos partilhados por jovens porto-alegrenses". Ciências Sociais em Perspectiva, 6 (11): 139-153.

BILLS, David \& HALLER, Archibald. (1984), "Socioeconomic development and social stratification: reassessing the Brazilian case". Journal of Developing Areas, 19: 59-69.

CAMPBELL, Angus; CONVERSE, Philip; MILLER, Warren \& STOKES, Donald. (1960), The American voter. Nova York/Londres, John Wiley.

CARMINES, Edward \& ZELLER, Richard. (1980), Measurement in the social sciences: the link between theory and data. Cambridge, Cambridge University Press.

CASTRO, Lúcia Rabello. (2008), "Participação política e juventude: do mal-estar à responsabilização frente ao destino comum". Revista de Sociologia e Política, 16 (30): 253-268.

CASTRO, Mônica M. M. (1994), Determinantes do comportamento eleitoral: a centralidade da sofisticação política. Rio de Janeiro, tese de doutorado, Instituto Universitário de Pesquisas do Rio de Janeiro.

CONVERSE, Philip. (1964), "The nature of belief systems in mass publics", in David Apter (org.), Ideology and sisconten, Nova York, Free.

COSTELO, Anna \& OSBORNE, Jason (2005), "Best practices in exploratory factor analysis: four recommendations for getting the most of your analysis". Practical Assessment, Research \& Evaluation, 10 (7): 1-9.

DELLI CARPINI, Michael \& KEETER, Scott. (1996), What Americans know about politics and why it matters. New Haven, Yale University Press. 
FINKEL, Steven \& ERNST, Howard. (2005), "Civic education in post-apartheid South Africa: alternative paths to the development of political knowledge and democratic values". Political Psychology, 26 (3): 333-364.

FLORENTINO, Renata. (2008), "Democracia liberal: uma novidade já desbotada entre os jovens". Opiniāo Pública, 14 (1): 205-235.

IBASE \& POLIS. (2005), "Juventude brasileira e democracia: participação, esferas e políticas públicas - relatório final”. Rio de Janeiro, Ibase.

ICHILOV, Orit. (2007), "Civic knowledge of high school students in Israel: personal and contextual determinants". Political Psychology, 28 (4): 417-440.

KING, Gary. (1986), "How not to lie with statistics: avoiding common mistakes in quantitative political science". American Journal of Political Science, 30 (3): 666-687.

KROSNICK, Jon. (1990), "Expertise and political psychology”. Social Cognition, 8 (1): 1-8.

KUKLINSKI, James \& QUIRK, Paul. (2002), "Conceptual foundations of citizen competence”. Political Behavior, 23 (3): 285-311.

LUSKIN, Robert. (1987), "Measuring political sophistication". American Journal of Political Science, 31 (4): 856-899.

LUSKIN, Robert. (1990), "Explaining political sophistication". Political Behavior, 12 (4): 331-361.

NAZZARI, Rosana Kátia. (2007), "Socialização política e capital social: empoderamento dos estudantes em Cascavel/PR". Anais do II Seminário Nacional Movimentos Sociais, Participaçāo e Democracia, 25 a 27 de abril.

NEUMAN, W. Russell. (1981), "Differentiation and integration: two dimensions of political thinking". The American Journal of Sociology, 86 (6): 1236-1268.

. (1986), The paradox of mass politics: knowledge and opinion in the American electorate. Cambridge, Harvard University Press.

NIEMI, Richard \& JUNN, Jane. (1998), Civic education: what makes students learn. New Haven, Yale University Press.

POWER, Timothy \& ZUCCO, Cezar. (2009), "Estimating the ideology of Brazilian legislati- ve parties, 1990-2005: a research communication". Latin American Research Review, 44 (1): 218-246.

REIS, Fábio W. \& CASTRO, Mônica M. M. (1992), "Regiōes, classe e ideologia no processo eleitoral brasileiro". Lua Nova, 26: 81-131.

RENNÓ, Lúcio. (2007), "Desigualdade e informação política: as eleiçōes brasileiras de 2002". Dados, 50 (4): 721-755.

SEARS, David \& VALENTINO, Nicholas. (1997), "Politics matters: political events as catalysts for preadult socialization". The American Political Science Review, 91 (1): 45-65.

SLOMCZYNSKI, Kazimierz, SHABAD, Goldie. (1988), "Can support for democracy and the market be learned in school? A natural experiment in post-communist poland". Political Psychology, 19 (4): 749-779.

SNIDERMAN, Paul; BRODY, Richard \& TETLOCK, Philip. (1991), Reasoning and choice: explorations in political psychology. Nova York, Cambridge University Press.

VERBA, Sidney; BURNS, Nancy \& SCHLOZMAN, Kay Lehman. (2003), "Unequal at the starting line: creating participatory inequalities across generations and among groups". The American Sociologist, Spring/Summer: 45-69.

VERBA, Sidney; SCHLOZMAN, Lehman \& BURNS, Nancy. (2005), "Family ties: understanding the intergenerational transmission of participation", in Alan S. Zuckerman (org.), The social logic of politics, Philadelphia, Temple University Press.

ZALLER, J. \& FELDMAN, S. (1992), "A simple theory of the survey response: answering questions versus revealing preferences". American Journal of Political Science, 36 (2): 579-616. 


\section{INFORMAÇÃO E CONCEITUAÇÃO: A DIMENSÃO COGNITIVA DA DESIGUALDADE POLÍTICA ENTRE JOVENS DE BELO HORIZONTE}

\section{Mario Fuks e Frederico Batista Pereira}

Palavras-chave: Conhecimento político; Sofisticação política; Socialização política; Jovens; Desigualdade política.

O presente artigo discute o conceito, a mensuração e os processos por meio dos quais os cidadãos adquirem conhecimento político. Discutimos, primeiramente, a elaboração analítica e a mensuração do conhecimento político em pesquisas empíricas na ciência política. Em seguida, criamos indicadores dos dois tipos principais de conhecimento: a informação factual e o conhecimento conceitual. O último passo consistiu em averiguar, por meio da análise estatística multivariada, os processos por meio dos quais os jovens adquirem os dois tipos de conhecimento.

\section{INFORMATION AND CONCEPT: THE COGNITIVE DIMENSION OF POLITICAL INEQUALITY AMONG THE YOUNG IN BELO HORIZONTE}

\section{Mario Fuks and Frederico Batista Pereira}

Keywords: Political knowledge; Political sophistication; Political socialization; The young; Political inequality.

This article discusses the concept, measurement, and processes by which individuals acquire political knowledge. We discuss, firstly, the debate concerning the concept and measurement of political knowledge in the empirical research. Next, we create indicators of the two main types of knowledge: factual information and conceptual knowledge. Finally we examine, through multivariate statistical analysis, the processes by which young people acquire the two types of knowledge.

\section{INFORMATION ET CONCEPTION LA DIMENSION COGNITIVE DE L'INÉGALITÉ POLITIQUE ENTRE JEUNES DE BELO HORIZONTE}

\section{Mario Fuks and Frederico Batista Pereira}

Mots-clés: Connaissance politique; Sophistication politique; Socialisation politique; Jeunes; Inégalité politique.

Cet article aborde le concept, la mesure et les processus par lesquels les citoyens acquièrent les connaissances politiques. Nous discutons, en premier lieu, la formulation analytique et la mesure des connaissances politiques dans la recherche empirique en sciences politiques. Nous créons, ensuite, des indicateurs de deux catégories principales de connaissances: l'information factuelle et la connaissance conceptuelle. La dernière étape est l'examen, par l'analyse statistique multivariée, des processus par lesquels les jeunes acquièrent les deux genres de connaissance. 